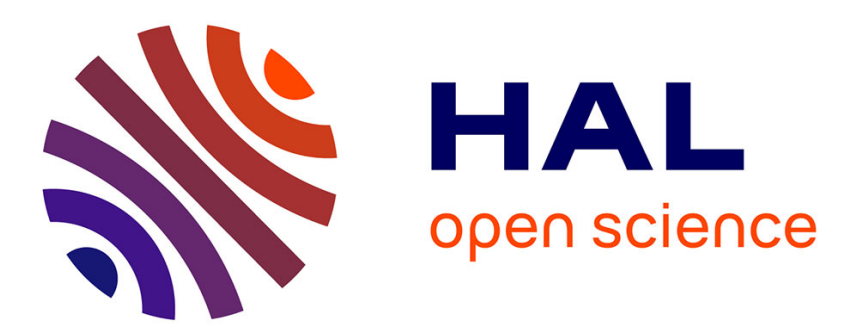

\title{
Temperature dependence of magnetic behaviour in very fine grained, spark plasma sintered NiCuZn Ferrites
}

Behzad Ahmadi, Karim Zehani, Martino Lobue, Vincent Loyau, Frédéric

\author{
Mazaleyrat
}

\section{- To cite this version:}

Behzad Ahmadi, Karim Zehani, Martino Lobue, Vincent Loyau, Frédéric Mazaleyrat. Temperature dependence of magnetic behaviour in very fine grained, spark plasma sintered NiCuZn Ferrites. Journal of Applied Physics, 2012, 111 (7), pp.07A5 10. 10.1063/1.3675983 . hal-00675776

\section{HAL Id: hal-00675776 https://hal.science/hal-00675776}

Submitted on 16 Mar 2012

HAL is a multi-disciplinary open access archive for the deposit and dissemination of scientific research documents, whether they are published or not. The documents may come from teaching and research institutions in France or abroad, or from public or private research centers.
L'archive ouverte pluridisciplinaire HAL, est destinée au dépôt et à la diffusion de documents scientifiques de niveau recherche, publiés ou non, émanant des établissements d'enseignement et de recherche français ou étrangers, des laboratoires publics ou privés. 
Temperature dependence of magnetic behaviour in very fine grained, spark plasma sintered $\mathrm{NiCuZn}$ Ferrites

Behzad Ahmadi, ${ }^{1, \text { a) }}$ Karim Zehani, ${ }^{1}$ Martino LoBue, ${ }^{1}$ Vincent Loyau, ${ }^{1}$ and Frederic Mazaleyrat ${ }^{1}$

SATIE, ENS Cachan, CNRS, UniverSud

61, avenue du President Wilson, F-94230 Cachan, France

Recently, using spark plasma sintering technique, a family of very fine grained, fully dense NiCuZn ferrites have been produced which show constant permeability up to several $10 \mathrm{MHz}$. These Ferrites can be used for filtering purposes in high frequency applications where a wide frequency band is required. In this paper we study the magnetization processes taking place in these nano grained materials, in the frequency interval of $100 \mathrm{kHz}$ to $5 \mathrm{MHz}$. Using a fluxmetric hysteresis graph, permeability, loss and $\mathrm{BH}$ loops are measured at different temperatures, from $-5^{\circ} \mathrm{C}$ to $110^{\circ} \mathrm{C}$. Results are compared to the behaviour of micrometric grain size Ferrites, which are commonly used for power electronic and high frequency applications.

a)Electronic mail: ahmadi@satie.ens-cachan.fr 


\section{INTRODUCTION}

In high frequency applications for filtering purposes, wideband magnetic components with tailored characteristics are usually needed ${ }^{1}$. Indeed, sintered MnZn and NiZn ferrites could provide an adequate response to this challenge $\mathrm{e}^{2,3}$. In this paper we focus on NiCuZn Ferrites which show wider frequency bandwidth and quite lower initial permeability comparing to the MnZn Ferrites.

Recently, using reactive Spark Plasma Sintering (SPS) technique ${ }^{4}{ }^{5}$ a family of very fine grained, fully dense NiCuZn ferrites have been produced which can provide components with wide bandwidth up to $30 \mathrm{MHz}$. In this paper the frequency range of $100 \mathrm{kHz}$ to 5 $\mathrm{MHz}$ is investigated, which could interest the power electronic designers. In this range of frequency, these nanograined materials still exhibit quasi static behaviour.

In order to study the mechanisms of magnetization and loss in these materials, first the quasi static behaviour is investigated through Rayleigh theory. In this way the reversible and irreversible parts of the magnetization are worked out and their dependence on temperature is discussed. This analysis is then completed by measurements at high frequency, up to several MHz, where the eddy current losses are still negligible for these materials. Results are compared with some recent works ${ }^{6,7}$ on micrometric grained materials and the influence of grain size is discussed.

\section{EXPERIMENTAL METHODS}

\section{Sample composition and micro structure}

The Samples studied in this paper, are toroial cores of internal and external diameters of $4 \mathrm{~mm}$ and $8 \mathrm{~mm}$ respectively. These cores are prepared from the material with the composition of $\mathrm{Ni}_{0.24} \mathrm{Cu}_{0.2} \mathrm{Zn}_{0.56} \mathrm{Fe}_{2} \mathrm{O}_{4}$. The oxides are milled in a planetary mill (Fritsch, Pulverisette) at $400 \mathrm{tr} / \mathrm{min}$ for $30 \mathrm{~min}$ to obtain the powder. The powder is then sintered by the reactive SPS method, under a uniaxial pressure of 50MPa and natural argon atmosphere under the following heat treatment:

A rise to $580^{\circ} \mathrm{C}$ within $3 \mathrm{~min}$, then maintained for $10 \mathrm{~min}$. A second rise to $800^{\circ} \mathrm{C}$ within 2 min then sintering for $5 \mathrm{~min}$. Final step is cooling to the room temperature within $5 \mathrm{~min}$. Table I, resumes some properties of these samples after sintering. Fig.1 shows the X-ray 


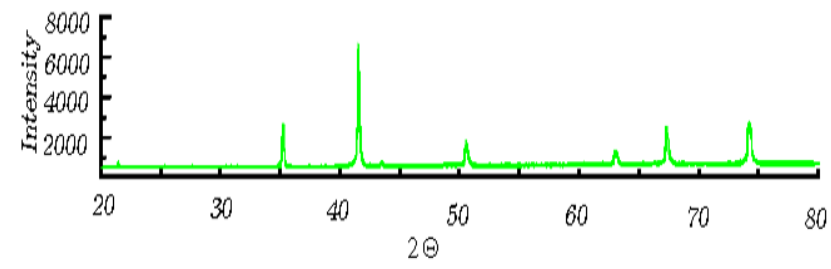

FIG. 1. X-Ray diffractogram of the samples prepared by SPS method under argon atmosphere

TABLE I. Electrical resistivity, dielectric permittivity, density and saturation magnetization of samples.

\begin{tabular}{llll}
\hline \hline$\rho(\Omega . m)$ & $\epsilon^{\prime}$ & $d_{r}\left(\mathrm{~g} / \mathrm{cm}^{3}\right)$ & $\sigma_{s}(m T)$ \\
340 & 84.3 & 5.030 & 385 \\
\hline \hline
\end{tabular}

diffractograms of these samples. Refining these diffractograms, by Rietveld method ${ }^{8}$, yields a lattice parameter of $841 \mathrm{pm}$ and an average grain size of $137 \mathrm{~nm}$. Neutron depolarization experiments made on polycrystalline Ferrites ${ }^{9,10}$ show that the nanometric grains in our materials are expected to be single domain.

\section{Magnetic characterization}

Hysteresis loops and loss are measured using a calibrated fluxmetric setup. Sinusoidal signals are provided by an HP33120A generator which are then amplified by an NF4055 (DC-10MHz) amplifier and applied on samples.

The operating temperature of the conventional passive probes ranges from $0^{\circ} \mathrm{C}$ to $50^{\circ} \mathrm{C}$. In order to extend the temperature range of the measurements, an active probe with operational amplifiers is designed. Input impedance of this probe is $3.3 \mathrm{M} \Omega$ and is calibrated for a temperature range of $-10^{\circ} \mathrm{C}$ to $150^{\circ} \mathrm{C}$. Primary current is measured through a resistive shunt, calibrated for this range of temperature. Sample are mounted on the probe and are kept in a temperature regulated chamber. Sample temperature is measured with a platinum resistance sensor (PT100), stacked on the material, and is monitored with a Keithley 2700 ohm meter. In order to prevent sample self heating during the measurements, 50 cycles of signal is applied on the sample for each measurement. Temperature is kept constant with the accuracy of $0.1^{\circ} \mathrm{C}$. 


\section{RESULTS AND DISCUSSION}

As depicted in Fig. 2, loss measurements for different frequencies reveal that the quasi static loss remains dominant up to $1 \mathrm{MHz}$ range, in these materials. For frequencies less than $1 \mathrm{MHz}$, material show the Rayleigh like loops. (Fig. 3). Descending and ascending parts of these loops can be expressed as ${ }^{11}$ :

$$
B=\left(\mu_{1}+\eta H_{m}\right) H \pm \frac{1}{2} \eta\left(H_{m}^{2}-H^{2}\right)
$$

The reversible and irreversible parts of the magnetization, when the magnetic flux changes from $-\mathrm{B}_{\mathrm{m}}$ to $\mathrm{B}_{\mathrm{m}}$, are equal to $2 \mu_{1} \mathrm{H}_{\mathrm{m}}$ and $2 \eta \mathrm{H}_{\mathrm{m}}^{2}$ respectively. Variations of reversible permeability $\left(\mu_{1}\right)$, irreversible permeability $\left(\eta \mathrm{H}_{\mathrm{m}}\right)$ and amplitude permeability $\left(\mathrm{B}_{\mathrm{m}} / \mathrm{H}_{\mathrm{m}}\right)$, for $15 \mathrm{mT}$ and $25 \mathrm{mT}$, are shown in the Fig. 4. For each BH loop, at a given temperature and frequency, $\mu_{1}$ and $\eta$ are identified by fitting theoretical and experimental curves using least squares method. These parameters are constant for all frequencies from $100 \mathrm{kHz}$ to $1 \mathrm{MHz}$, for a given temperature. For frequencies higher than $1 \mathrm{MHz}, \mathrm{BH}$ loops deviate from Rayleigh theory slightly.

The whole permeability is decreasing continuously with temperature. This point is in agreement with the measured initial permeability for low frequencies $i^{12}$, where it is shown that by reaching the grain size of about $300 \mathrm{~nm}$, initial permeability is always decreasing with temperature.

This behaviour is mainly due to diminution of the reversible mechanism contribution to the magnetization process. One can observe on the identified curve(Fig. 4), that the reversible

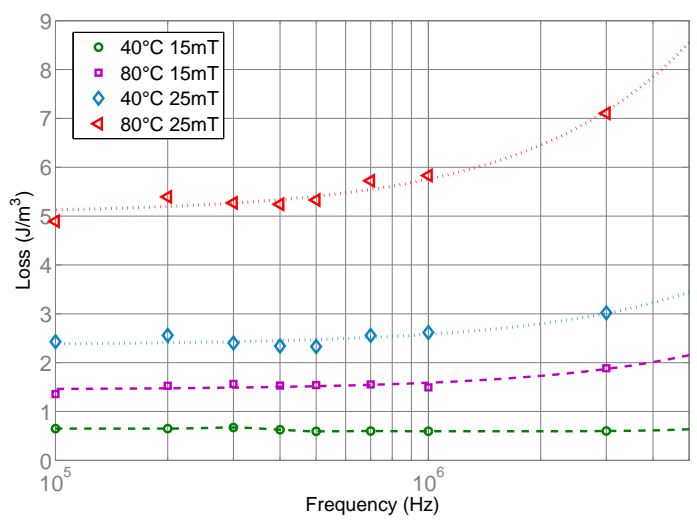

FIG. 2. Magnetic energy Loss vs frequency of spark plasma sintered Ferrites. 
permeability is decreasing rapidly by the increase of temperature and the irreversible part of the permeability is increasing linearly with temperature.

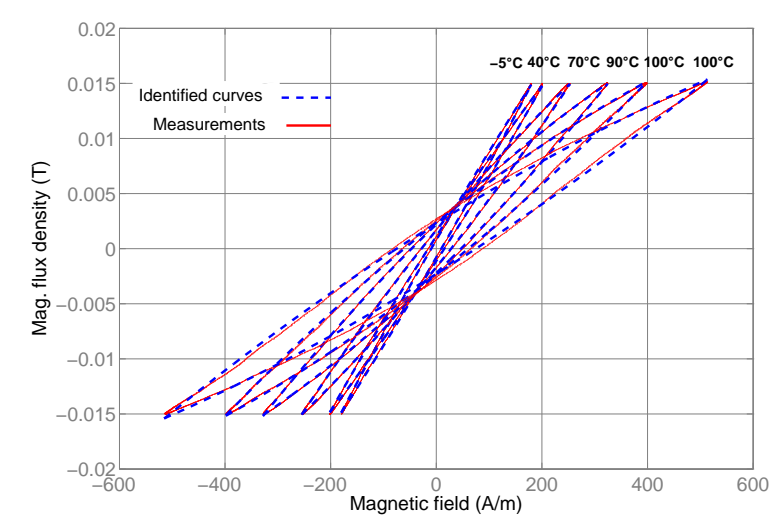

FIG. 3. Measured Rayleigh like loops for $500 \mathrm{kHz}$ and $15 \mathrm{mT}$ at different temperatures

It should be highlighted that reversible part of the permeability remains constant for $15 \mathrm{mT}$ and $25 \mathrm{mT}$ and have the same temperature behaviour. The irreversible part is increased slightly. To investigate this phenomenon and determine the flux density limit of this description, hysteresis loops are measured for different magnetic flux densities at room temperature. Fig. 5 shows the identified parts of the relative permeability at $25^{\circ} \mathrm{C}$. The reversible permeability remains constant up to $30 \mathrm{mT}$ and the irreversible part of the permeability increase almost linearly with the magnetic flux density. The temperature limit of this behaviour decrease with flux density. This description is valid for $15 \mathrm{mT}$ up to $110^{\circ} \mathrm{C}$ and and for $25 \mathrm{mT}$ up to $90^{\circ} \mathrm{C}$.

Within the validity of this description, it can be deduced that the mechanisms which are responsible for the dissipative behaviour, produce losses which increase continuously with temperature. As the grains in these materials are single domain, there is no domain wall inside the grains. Dissipative behaviour is then related to the magnetization rotation. This is consistent with analyses of Fiorillo et al. ${ }^{6}$ which show that the losses related to the domain wall displacement reduce with temperature and those related to the magnetization rotation mechanism increase with temperature.

For the same composition of the material $(\mathrm{Ni} / \mathrm{Zn}=0.43)$ with micro metric grains $(\approx 5 \mu \mathrm{m})$, it is shown that the permeability is increasing with temperature and dissipative behaviour is minimized at a temperature between $5^{\circ} \mathrm{C}$ to $50^{\circ} \mathrm{C}^{7}$. 


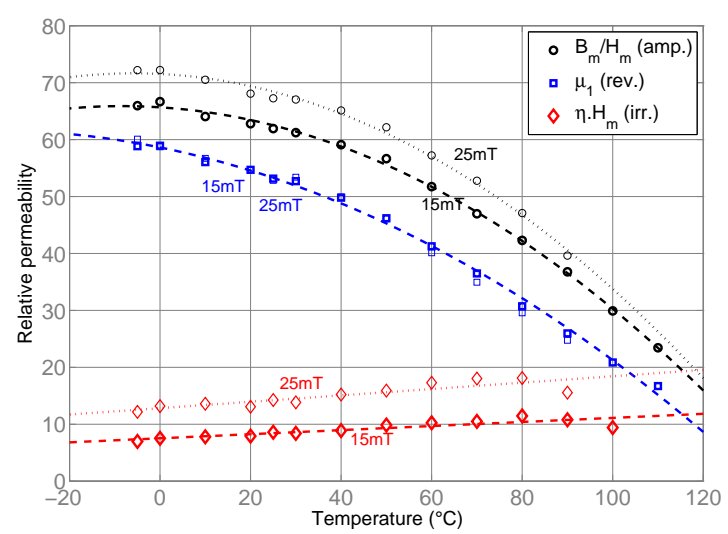

FIG. 4. Identified reversible $\left(\mu_{1}\right)$, irreversible $\left(\eta \mathrm{H}_{\mathrm{m}}\right)$ permeability and measured amplitude permeability $\left(\mathrm{B}_{\mathrm{m}} / \mathrm{H}_{\mathrm{m}}\right)$ at $500 \mathrm{kHz}$ for different temperatures.

Measured energy losses at different temperatures and different frequencies are shown in Fig. 6. Dissipative behaviour is increasing with temperature for all frequencies. Losses at $100 \mathrm{kHz}$ correspond to quasi static behaviour which can be described with Rayleigh theory. For a magnetic flux density of $15 \mathrm{mT}$, up to $60^{\circ} \mathrm{C}$, losses are identical for all frequencies up to $3 \mathrm{MHz}$; this temperature is limited to $40^{\circ} \mathrm{C}$ for $25 \mathrm{mT}$. Deviation is more important at high temperatures : for $15 \mathrm{mT}$ one can observe the energy loss $\mathrm{E}_{3 \mathrm{MHz}, 100^{\circ} \mathrm{C}}=1.65 \mathrm{E}_{100 \mathrm{kHz}, 100^{\circ} \mathrm{C} \text { and }}$

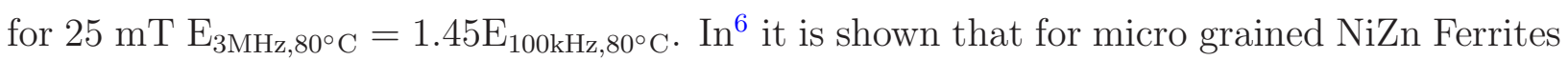
losses decrease with temperature, from $20^{\circ} \mathrm{C}$ to $100^{\circ} \mathrm{C}$, at low frequencies and increases with temperature at high frequencies where the rotation mechanism is dominant. In our material the quasi static loss and dynamic loss are both increasing with temperature.

\section{CONCLUSIONS}

The quasi static loss and frequency behaviour of single domain nano metric grain, $\mathrm{NiZnCu}$ Ferrite are investigated. It is shown that Rayleigh theory can describe the behaviour of these Ferrite up to $\mathrm{MHz}$ range and several $10 \mathrm{mT}$. Using this theory and measuring $\mathrm{BH}$ loops at different temperatures, a linear increase of irreversible magnetization with temperature is deduced. These parameters can be obtained with a single BH loop measurement and can provide an estimation of losses up to $\mathrm{MHz}$ range for these materials, which can interest power electronic component designers. 


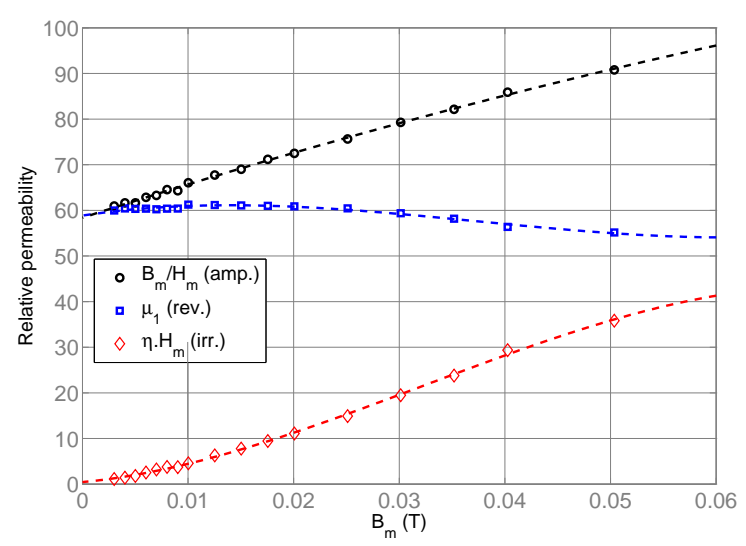

FIG. 5. Identified reversible $\left(\mu_{1}\right)$, irreversible $\left(\eta \mathrm{H}_{\mathrm{m}}\right)$ permeability and measured amplitude permeability $\left(\mathrm{B}_{\mathrm{m}} / \mathrm{H}_{\mathrm{m}}\right)$ at $200 \mathrm{kHz}$ for different magnetic flux intensity.

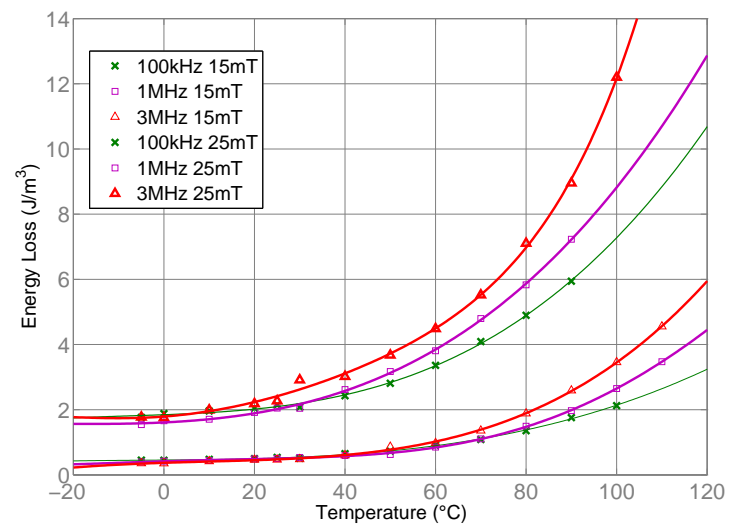

FIG. 6. Energy loss for different frequencies and different temperatures.

\section{REFERENCES}

${ }^{1}$ B. J. Pierquet, T. C. Neugebauer, and D. J. Perreault, IEEE Transactions on Power Electronics 21, 1815 (2006).

${ }^{2}$ F. Fiorillo, E. Ferrara, M. Coisson, C. Beatrice, and N. Banu, Journal of Magnetism and Magnetic Materials 322, 1497 (2010).

${ }^{3}$ R. Lebourgeois, J. Ganne, G. Peyresoubes, W. Rebernak, A. Adenot, and O. Acher, Journal of Magnetism and Magnetic Materials 254-255, 608 (2003).

${ }^{4}$ K. Zehani, F. Mazaleyrat, V. Loyau, and E. Laboure?, Journal of Applied Physics 109, 07 A504 (2011). 
${ }^{5}$ R. Valenzuela, Z. Beji, F. Herbst, and S. Ammar, Journal of Applied Physics 109, 07 A329 (2011).

${ }^{6}$ F. Fiorillo, C. Beatrice, M. Coisson, and L. Zhemchuzhna, IEEE Transactions on Magnetics 45, 4242 (2009).

${ }^{7}$ A. Lucas, R. Lebourgeois, F. Mazaleyrat, and E. Laboure, Journal of Magnetism and Magnetic Materials 323, 735 (2011).

${ }^{8}$ H. M. Rietveld, Journal of Applied Crystallography 2, 65 (1969).

${ }^{9} \mathrm{P} . \quad$ J. van der Zaag, M. Kolenbrander, and M. T. Rekveldt, Journal of Applied Physics 83, 6870 (1998).

${ }^{10}$ P. J. van der Zaag, Journal of MMM 196-197, 315 (1999).

${ }^{11}$ R. M. Bozorth, Ferromagnetism, 1st ed. (Wiley-IEEE Press, 1993) pp. 489-494.

${ }^{12} \mathrm{M}$. Johnson, A. Noordermeer, M. Severin, and W. Meeuwissen, Journal of Magnetism and Magnetic Materials 116, 169 (1992). 